Mr. S. I. Tomkeieff had visited Fen in Norway, where the rocks, closely comparable with those at Alnö, were described in a classic paper by W. C. Brögger in 1921. He has no doubt about the magmatic origin of the carbonate rocks in that district.

Prof. S. J. Shand claimed that the limestones at Alnö and Fen, and at eight other localities which he listed, had been or ultimately would be proved to be derived from sedimentary or metamorphosed sedimentary limestones. He described two areas of alkali-rich rocks-Haliburton, Ontario, and Sekukuniland, Transvaal - where he regards it as demonstrable that carbonate-rocks associated with nepheline-syenite have been derived by the incorporation of sedimentary or metamorphic limestones by igneous magma.

Prof. C. E. Tilley admitted that the limestonesyntexis theory is applicable in certain places to a limited extent and he believes that the limestone 'intrusions' in the Haliburton and Bancroft areas present certain peculiarities differentiating them from the other occurrences, but he claimed magmatic origin for every other example of limestone associated with alkali-rich rocks in Prof. Shand's list. He mentioned especially Magnet Cove, Arkansas, and Palabora, Transvaal, and he added two new examples: Iron Hill, Colorado, and Kabossero at the head of the White Sea.

The claim for magmatic origin of some of these limestones seems to rest on good field evidence, but it needs to be supported by a credible explanation of how magmatic limestones can be formed and why they are associated with alkali-rich intrusions. To this task Dr. von Eckermann devoted the last half of his address. He outlined the possible processes which might have effected the formation at the base of the Jotnian sheetintrusions of a nepheline-syenite magma rich in potash, carbon dioxide, fluorine and chlorine, and he traced the possible history of such a magma as it stoped its way upwards to a point at which the concentrated volatiles shattered the roof and more or less pure carbonates filled the conical fractures in the surrounding rock. Mr. Tomkeieff also was able to suggest a possible petrogenetic scheme for the rocks of Fen. He regards carbon dioxide as probably originally present in many rock magmas but lost by most during consolidation. Where it is retained, it must have a profound effect on the course of differentiation. While Dr. Eckermann made no claim that the explanation he had put forward applied outside Fennoscandia, Mr. Campbell Smith, referring to the rocks of the Chilwa Series of Southern Nyasaland, said that there are so many resemblances between them and the rocks at Alnö and Fen that processes which were active in Fennoscandia in the Archæan must have been operative at the Chilwa vents in postKarroo times. He said that in Nyasaland the problem is to explain the close connexion between the formation of pure orthoclase-rocks (remarkably rich in potash), their brecciation, the alteration of the country rocks, the supply of material for and the emplacement of the crystalline limestone, and the subsequent intrusion of alkali-rich rocks.

When the results of Dr. von Eckermann's work are published, it may be found that all these closely related events will find their places in the scheme of differentiation of which during the discussion he gave a brief description, but which lack of space here compels us to omit.

\title{
Vibration in Engineering
}

$\mathrm{F}^{\mathrm{o}}$ R the past few years, the council of the British Association, in co-operation with the various sections, has selected a number of scientific topics which are of direct interest to the general public, and by means of symposia or otherwise, to which workers in the particular fields concerned have contributed, general reviews of our present knowledge and the problems still to be solved have been arranged. Among the subjects chosen for the Cambridge meeting was vibration, a phenomenon which, in this mechanical age, is in daily evidence to every one of us, and the importance of which is very great. The engineer is concerned with its results upon the structure in which it occurs, which, in an aeroplane, for example, may be disastrous, and in any event will have a deterior. ating effect. The ordinary person, be he traveller in motor-car, train, ship or aeroplane, is more concerned with the discomfort (and even, maybe, injury to health), which accompanies continuous vibration. From whichever point of view it is regarded, therefore, vibration is a phenomenon which everyone desires to see eliminated or reduced to a minimum.

Any elastic structure, when disturbed from rest and released, will vibrate freely for some time in one of a number of possible modes, the particular one resulting depending upon the restraints imposed on the structure and upon the method of disturb. ance. The frequencies of these modes are called the 'natural' frequencies of the system. When a bridge or ship, for example, is subjected to a 
sudden load, it will vibrate in one of these natural modes, but the vibration will be rapidly damped out. When a periodic disturbing force is applied to such a structure, vibration will ensue of the same frequency as the disturbing force, the amplitude depending upon the magnitude of the force. This type is termed 'forced' vibration. When the frequency of the disturbing force is equal to that of one of the natural modes of vibration of the structure, a state of resonance occurs, and, theoretically, for a completely undamped structure, the amplitude will become infinite. Actually, the movement is restricted by the damping of the supports and in the material, and by the fact that the restraints alter completely when the amplitude becomes large; but nevertheless, very serious vibration may and does result in all types of engineering structures under such resonant conditions.

In any motor-car, ship, aeroplane, or other selfpropelled vehicle, there are several sources in the machinery from which periodic disturbing forces may arise, and therefore very few such structures are free from forced vibration of one form or another. In order that the amplitude of this should be so small as to be unimportant to passengers, the engineer must do everything possible to balance the machinery so that the magnitude of the out-of-balance forces may be small. If this cannot be achieved by such means, a vibration damper may be used. Such a device was described and shown in action at Cambridge by Prof. C. E. Inglis in introducing the symposium on the subject in Section G (Engineering). It consists of a small spring-supported mass, of about one per cent of the weight of the structure, and attached to it, and tuned to vibrate at the same frequency. Under such conditions it is capable of reducing the vibration of the main structure to very small amounts indeed. Similar devices have been developed for eliminating torsional vibrations in engine shafts.

The most serious cases of vibration, whether considered from a structural or a comfort point of view, are those in which resonance occurs. Under such conditions even a very small residual disturbing force may cause large amplitudes of vibration, and in a completed structure suffering from this type it is usually necessary to alter the frequency of the disturbing force and so destroy the resonance. This, however, cannot always be done without sacrifices in other directions. As Dr. F. H. Todd pointed out, when dealing with ship vibration, if the revolutions of the main engines have to be reduced by ten per cent to avoid resonance with a natural frequency of the hull, this entails, if no other changes are made, a loss of speed of ship of the same order. To recover this loss, a new set of propellers will be necessary, and it is not then always a practical solution, since in certain types of engines, particularly oil engines, it is not permissible to increase the pressures in the cylinders in order to develop the original power at the lower revolutions. One cannot usually destroy resonance in a ship by going to higher revolutions, since within the possibilities of a completed engine the margin will be small, and as soon as bad weather is encountered the revolutions will fall into the resonant range again.

It is evident that the possibility of such resonant vibration should be considered in the early stages of any design in order that the frequencies of the engine forces should not coincide with any of the natural frequencies. Fortunately, as Prof. Inglis pointed out, vibration is one phenomenon in engineering which can be dealt with by precise mathematical methods, and we can calculate the natural frequencies of many designs while they still exist only on paper, and so ensure an absence of resonant vibration in the completed structure. Such calculations can be made for a ship, for example, taking into account the variation in load and strength along the length of the hull girder. A very important consideration in such a calculation appears to be the inclusion of the effect of the surrounding water. This influences the vibration by its damping effect, which will restrain the amplitude at resonance, and also by the virtual inertia effect due to the loss of energy entailed by the movement imparted to the water underneath and alongside the hull as it vibrates. The amount of this virtual inertia can be determined mathematically, and is equivalent to an addition to the hull weight of about its own magnitude for normal ships, and for a wide, shallow-draft ship the increase of inertia may be three times the vessel's displacement. These quantities seem large at first sight, but Dr. Todd showed that the calculated frequencies so obtained for the primary vertical vibration agree remarkably well with the recorded natural frequencies for some sixteen vessels on which he has obtained their values experimentally.

In aircraft, similar vibration troubles arise in the fuselage and air-screws. In many cases these are due to forces originating in the engines, and as before special attention to the balancing and care in avoiding resonant speeds is essential. In addition, vibration can be caused by aerodynamic forces. Examples of such cases were given by Major B. C. Carter, including tail flutter, wing flutter and flutter of air-screw blades. In certain conditions of flutter, instability may arise, and portions of the structure be torn away. Knowledge on this branch has increased greatly of recent years, and enough is now known about it to avoid such disastrous effects. Any new design 
of air-screw is also subject to exhaustive tests to ensure that it is free from flutter before being used in machines.

In order to study vibration of aircraft in flight, very delicate instruments are necessary, and some of those developed at the Royal Aircraft Establishment were described by Major Carter. One vibrograpb designed there records the amplitude on a photographic film, and can be operated by the pilot during flight by remote control, and yet is vary compact and only weighs a little more than two pounds. To obtain records of air-screw blade tip vibration in flight, a camera is secured to and rotated with the hub, the motion of the blade tip being recorded on a film by means of the relative movement of a small electric light bulb cemented to the tip of the blade. Other modern methods include the use of photo-electric cells, the variation of the resistance of a body under stress and cathoderay oscillographs. It is evident that all the latest developments of the electrical and physical sciences are being adopted in these instruments.

One aspect of the vibration problem touched upon by all three speakers at the symposium was the use of elastic mountings for prime movers, and this is a device which is being developed very rapidly, particularly in the design of motor vehicles. Such mountings bring with them their own problems, but we can look forward to a progressive improvement in comfort in all forms of transport by the successful elimination of vibration through their use. Much remains to be done in this way, but it was evident from this discussion at Cambridge that the engineering profession is fully alive to the necessity and is progressing rapidly in all its many and varied branches.

\section{Incremental Permeability of Special Steels}

\section{$\mathrm{T}$} HE importance now attached to the incremental permeability of silicon-steel and of nickel-iron alloys arises from the use of these materials for the cores of transformers and chokes in communication apparatus. Under these conditions, the magnetization is due to a continuous steady current upon which a variation is imposed either by modulation or by separate coils carrying alternating currents. Generally, the amplitude of the imposed wave is not great enough to reduce the steady magneto-motive force to zero, so that the value of the induction rises and falls as the resultant magneto-motive force changes; but it does not reverse. The calculation of the induced electromagnetic force in a secondary coil in these circumstances is fraught with peculiar difficulties.

Adopting the usual convention and indicating magnetic induction by $B$, magnetic force by $H$ and permeability, $B / H$, by $\mu$, then if the mean value of $B$ is not high and its variation small, the mean ratio $B / H$ over the change will approach the value of $\mu$ as measured and used for simple alternating currents. But as the mean value about which $B$ varies gets nearer to the saturation region of the iron, and particularly when the imposed variation is large, not only does the mean value of $\mu$ fall rapidly, but also its instantaneous value varies considerably. The consequences are (1) that the prediction of a secondary induced E.M.F. is difficult; (2) that if the imposed variation of $H$ be sinusoidal, the wave form of $B$ will be distorted; (3) that if the imposed variation of $B$ be sinusoidal, the wave form of $H$ will be distorted; (4) that losses associated with given variations in $B$ and $H$ become difficult to measure and very different from those in the same iron under simple alternating current conditions. Yet makers of communication apparatus must know what results they may expect from the material that they purchase, so that some method of specifying and of testing the quality of steel for these purposes is badly needed.

This was pointed out by Dr. L. G. A. Sims at a meeting of Section G (Engineering) of the British Association at Norwich (1935), and he added that the British Standards Institution specification for transformer steels (No. 601), which had been published that year, would not serve for these new purposes. Section G, recognizing the importance of the matter, asked Dr. Sims to ascertain what was being done, both in England and abroad, and to report at the Blackpool meeting in the following year. As a result, a questionnaire containing eleven questions was sent out from the University of Birmingham, and an analysis of the replies was presented at the British Association meeting of 1936, representatives of the British Standards Institution being present. On seven of the questions, world opinion was sufficiently unanimous to enable Section $G$ to ask that tests should be begun upon silicon steels based upon an alternating current method of test, sinusoidal variation of induction at 50 cycles per second and with samples in the form of a ring.

In February, 1937, the British Standards Institution formed a committee to consider the drafting of a specification based upon these tests and the extension of such tests to cover the much 